Post-print version of:

Publisher: Elsevier

Journal paper: International Journal of Fatigue 2018, 106 208-218

Title: Determination of the fatigue critical distance according to the Line and the Point Methods with rounded V-notched specimen

Authors: C. Santus, D. Taylor, M. Benedetti

Creative Commons Attribution Non-Commercial No Derivatives License

$$
\text { (c) }(i)(9)
$$

DOI Link: https://doi.org/10.1016/j.ijfatigue.2017.10.002 


\title{
Determination of the fatigue Critical Distance according to the Line and the Point Methods with rounded V-notched specimen
}

\author{
C. Santus ${ }^{\mathrm{a}, *}$, D. Taylor ${ }^{\mathrm{b}}$, M. Benedetti ${ }^{\mathrm{c}}$ \\ ${ }^{a}$ Department of Civil and Industrial Engineering, University of Pisa, Italy. \\ ${ }^{b}$ Department of Mechanical \& Manufacturing Engineering, Trinity College Dublin, Ireland. \\ ${ }^{c}$ Department of Industrial Engineering, University of Trento, Italy.
}

\begin{abstract}
The critical distance length should in principle be deduced from the plain specimen fatigue limit and the threshold stress intensity factor range. However, the threshold range is difficult to measure experimentally, hence this length is usually obtained by means of a notched specimen. The critical distance inverse search, both according to the Line and the Point Methods, is presented in this paper referring to a relatively sharp V-notched specimen. Precise indications about the geometry parameters are given along with a complete analytical procedure to easily obtain the critical distance. A sensitivity analysis is discussed, providing evidence of a critical distance range for a well-posed inversion problem.
\end{abstract}

Keywords: Critical Distance determination; inverse search; Line Method; Point Method; rounded V-notched specimen.

\footnotetext{
${ }^{*}$ Corresponding author: Ciro Santus

Ph. +39 (0)502218007

Email address: ciro.santus@ing.unipi.it (C. Santus)
} 


\section{Nomenclature}

LM, PM Line Method and Point Method.

$\Delta K_{\text {th }} \quad$ Threshold stress intensity factor range.

$\Delta \sigma_{\mathrm{fl}} \quad$ Plain specimen fatigue limit range.

$L \quad$ Critical distance obtained with the LM.

$x, y \quad$ Local coordinates for the notch stress distribution.

$\sigma_{y} \quad$ Notch axial stress.

$\sigma_{\mathrm{N}} \quad$ Notched specimen (net) nominal stress.

$\Delta \sigma_{\mathrm{N}, \mathrm{fl}} \quad$ Notched specimen nominal stress, fatigue limit range.

$K_{\mathrm{f}} \quad$ Fatigue stress concentration factor.

D Specimen bar diameter.

$R \quad$ Notch radius.

A Notch depth.

$\rho \quad$ Notch radius ratio.

$r \quad$ Dimensionless notch radius.

a Dimensionless notch depth.

$\xi \quad$ Dimensionless $x$ local coordinate.

$\alpha \quad$ Notch angle.

$s \quad$ Williams' power law singularity exponent.

$K_{\mathrm{N}} \quad$ Notch-Stress Intensity Facotr (N-SIF).

$K_{\mathrm{N}, \mathrm{U}} \quad \mathrm{N}-\mathrm{SIF}$ for unitary nominal stress.

$K_{\mathrm{N}, \mathrm{UU}} \quad \mathrm{N}-\mathrm{SIF}$ for unitary nominal stress and unitary half diameter.

$l \quad$ Dimensionless critical distance obtained with the LM.

$l_{0} \quad$ Dimensionless singular term critical distance obtained with the LM.

$L_{0} \quad$ Singular term critical distance obtained with the LM.

$l_{\min } \quad$ Minimum limit for the range of accurate critical distance determination.

$l_{\max } \quad$ Maximum limit for the range of accurate critical distance determination.

$f(l) \quad$ Correction function relating to the sharp and the rounded notch LM average stresses.

$\gamma(l) \quad$ Inversion function for the LM critical distance determination.

$\gamma_{\min } \quad$ Minimum value of the inversion function range.

$\gamma_{\max } \quad$ Maximum value of the inversion function range. 
$\beta \quad$ Line slope of the LM inversion function.

$p_{1}, \ldots, p_{4} \quad$ Model function coefficients for $l_{\min }$

$q_{1}, \ldots, q_{4} \quad$ Model function coefficients for $\gamma_{\min }$

$c_{1}, c_{2}, c_{3} \quad$ Model function coefficients for $l_{\max }$

$l_{0}^{\prime} \quad$ Dimensionless singular term critical distance obtained with the PM.

$L_{0}^{\prime} \quad$ Singular term critical distance obtained with the PM.

$l^{\prime} \quad$ Dimensionless critical distance obtained with the PM.

$L^{\prime} \quad$ Critical distance obtained with the PM.

$f^{\prime}\left(l^{\prime}\right) \quad$ Correction function relating to the sharp and the rounded notch PM stress.

$\gamma^{\prime}\left(l^{\prime}\right) \quad$ Inversion function for the PM critical distance determination.

$\delta_{1}, \ldots, \delta_{5} \quad$ Coefficients for the PM polynomial inversion function.

$S, S^{\prime} \quad$ Critical distance sensitivity with respect to $K_{\mathrm{f}}$ for LM and PM respectively.

$l_{0, n}^{\prime}, l_{n}^{\prime} \quad$ Iterative $l_{0}^{\prime}, l^{\prime}$ values for the proposed direct problem numerical calculation.

\section{Introduction}

The theory of critical distances introduces a material length which inherently relates the notch sensitivity to the local radius of a specimen or a component, both under monotonic fracture and fatigue loading $[1,2]$. Of the various formalisations, the most common are the Line Method (LM) and the Point Method (PM), which are both considered in this paper. The Area and the Volume methods are also available. However, according to Taylor and Wang [3], PM is the most accurate on variously notched specimens. When a multiaxial fatigue criterion is required, combined with a high gradient stress condition, several approaches may be followed such as the Volume method along with the Findley criterion [4]. The PM has been extensively applied together with the Modified Wöhler Curve Method (MWCM) critical plane criterion [5], and this approach was recently extended to the fretting fatigue $[6,7,8,9,10]$. The life assessment of metallic components under fretting loading has also been performed by applying a critical plane-based multiaxial fatigue criterion, proposed by Carpinteri and co-workers, in conjunction with the PM [11, 12]. Another application of interest for the critical distance is the shot peened notch, where a compressive residual stress has a dominant role to improve the fatigue strength. The LM has been found to be more appropriate to take into account the high gradient residual stress distribution, with a specific profile, which cannot be accurately captured by a single point (PM) approach [13, 14]. Finally, other methods such as the Implicit Gradient [15] and the Gradient Elasticity [16, 17, 18] entail advanced stress 
analysis yet still require a material dependent length.

The fatigue critical distance is generally determined by combining the threshold stress intensity factor range $\Delta K_{\mathrm{th}}$, with the plain specimen fatigue limit range $\Delta \sigma_{\mathrm{fl}}$ :

$$
L=\frac{1}{\pi}\left(\frac{\Delta K_{\mathrm{th}}}{\Delta \sigma_{\mathrm{fl}}}\right)^{2}
$$

Reference values for $\Delta K_{\mathrm{th}}$ and $\Delta \sigma_{\mathrm{fl}}$ can be found in dedicated papers and books such as Ref. [1]. However, the data derived from the literature may refer to a material with a slightly different composition, even if the nomenclature is the same, or with a different heat treatment. Without any reference data, the threshold stress intensity factor range has to be found experimentally, for example by implementing the ASTM E647 standard [19]. However some issues need to be considered:

- though well described in the ASTM standard, the experimental procedure is challenging and a specific equipment is required;

- when the material is available in bars, instead of plates, a large size diameter is required in order to have enough volume to produce the specimen itself;

- the fatigue crack growth test is usually performed on a very few samples, or even a single specimen, thus without a sound statistical significance;

- after the specimen precracking, the material at the crack tip experiences damage, residual stress and plasticity, while the critical distance is aimed at initially undamaged components where notches are just produced by machining.

For these reasons, as an alternative to fracture mechanics testing, one of the critical distance methods can be considered in order to be able to find the length that matches the notched and the plain specimen strengths, or two notches with different severities. This approach can be found in several papers, especially those regarding monotonic fracture, such as Li et al. [20], Yin et al. [21], Cicero et al. [22], Voiconi et al. [23], where the threshold is replaced by the fracture toughness $K_{\text {Ic }}$, and the inherent strength $\sigma_{0}$ has to be considered rather than the fatigue limit. Susmel and Taylor [24] extensively applied this principle both for monotonic fracture and fatigue loadings, and they found and validated a large material database of $K_{\mathrm{Ic}}$ and $\Delta K_{\mathrm{th}}$. The same approach was also presented for finite fatigue life under torsional loading [25].

In this paper, the determination of the critical distance without the fracture mechanics test is obtained with a dedicated notched specimen. An analytical formulation is also provided to straightforwardly calculate the critical distance lengths both according to the LM and the PM, without the need of a specific finite element analysis, 
having obtained the required coefficients with accurate simulations. The sensitivity of the critical distance with respect to the experimental data is then investigated in order to recommend an optimal specimen geometry. As suggested by Taylor [26], a reliable estimate of the critical distance can be obtained with sharply-notched specimens. In fact, this paper provides a range of accurate predictions which reveal that the minimum limit of this range depends on the notch radius.

In principle any kind of notch type could be exploited for this inversion analysis. However, in order to avoid edge effects and intermediate plain stress to plain strain conditions, plate specimens were not considered as a reference geometry. The circumferentially notched cylindrical bar specimen was therefore selected for this study. U-notch was not considered the best solution, since the local radius cannot be very small. On the other hand, sharp notch and easy manufacturing can be obtained with a small radius V-notch and a relatively open angle, e.g. $60^{\circ}$ or $90^{\circ}$, as shown by Campagnolo et al. [27] and Berto et al. [28] respectively.

\section{V-notched specimen FE modelling}

A series of linear elastic plane axisymmetric Finite Element (FE) simulations were performed to obtain the numerical solutions and then provide the coefficients for the formulation analytically proposed. The dimensions of the notched specimen are (Fig. 1): the bar diameter $D$, the notch depth $A$ (defined up to the deepest point, both sharp and rounded notches), the opening angle $\alpha$ and the notch radius $R$. The load type investigated is axial, and the nominal (net) notch stress $\sigma_{\mathrm{N}}$ is defined as the uniform ligament stress.

(a)

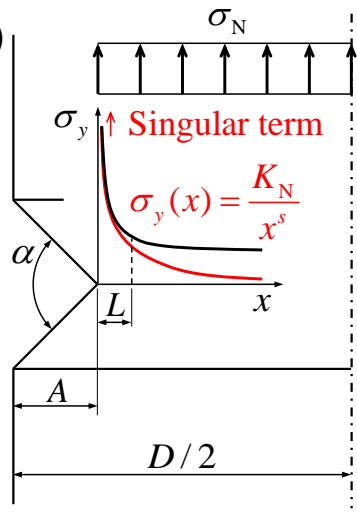

(b)

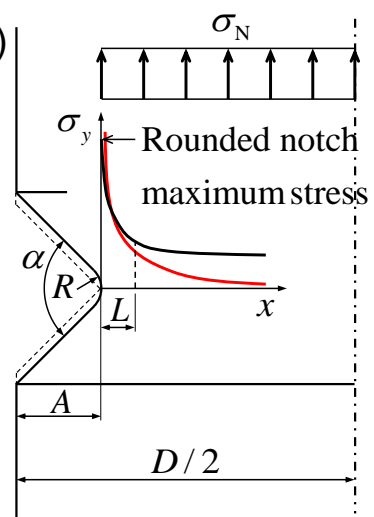

Figure 1: Specimen dimensions and axial stress distributions for: (a) sharp V-notch and (b) rounded V-notch.

Clearly, if the notch radius is zero (or assumed as zero), the stress distribution is unbounded and the singular term is the dominant part of the linear elastic solution. After introducing a certain notch radius, the stress distribution features a (bounded) maximum stress at the notch surface point, however the stress gradient ahead of the notch tip still resembles the singular term distribution. 


\subsection{Sharp V-notched specimen}

Initially, the analysis focused on the perfectly sharp notch (zero radius). The singular term of the local stress solution is:

$$
\sigma_{y}(x)=\frac{K_{\mathrm{N}}}{x^{s}}
$$

where $K_{\mathrm{N}}$ is the Notch-Stress Intensity Factor (N-SIF) with units $\left[\mathrm{MPa} \mathrm{mm}{ }^{s}\right]$ and $s$ is the power law singularity exponent, or degree of singularity, which obviously is dimensionless. This exponent $s$ was obtained by solving the Williams' problem [29] for a local plane sharp notch. The dependence on the opening angle $\alpha$ is shown in Fig. 2 in agreement with Refs. [30,31]. The accurate values of the exponent $s$ for the two most common notch angles $\alpha=60^{\circ}$ and $\alpha=90^{\circ}$ are also reported in the graph.

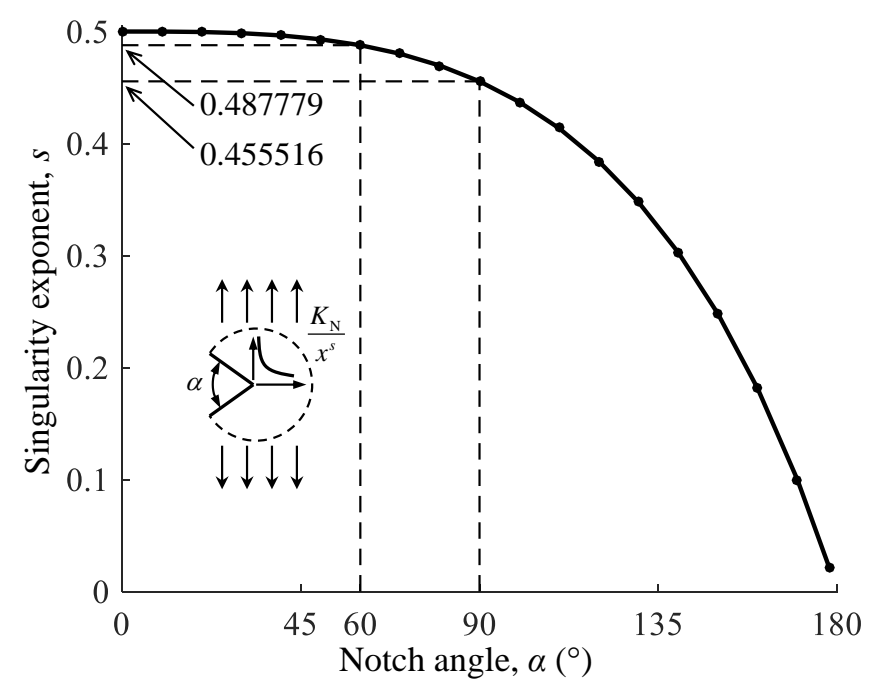

Figure 2: Dependence of the Williams' power law singularity exponent on the notch opening angle and specific values for $\alpha=60^{\circ}$ and $\alpha=90^{\circ}$.

The stress linearity allows the definition of a unitary nominal stress N-SIF:

$$
\sigma_{y}(x)=\sigma_{\mathrm{N}} \frac{K_{\mathrm{N}, \mathrm{U}}}{x^{s}}
$$

The self-similarity of the solution implies that the problem can be rescaled with respect to a dimension that represents the specimen size. The reference dimension chosen was $D / 2$, thus obtaining the following definitions: $a=A /(D / 2), r=R /(D / 2)$. Hence, Eq. 3 is rewritten as follows:

$$
\sigma_{y}(\xi)=\sigma_{\mathrm{N}} \frac{K_{\mathrm{N}, \mathrm{UU}}}{\xi^{s}}
$$

where $\xi=x /(D / 2)$ and $K_{\mathrm{N}, \mathrm{UU}}=K_{\mathrm{N}, \mathrm{U}} /(D / 2)^{s}$ which is the dimensionless (net) N-SIF for unitary nominal stress and unitary scaling length, i.e. when the specimen radius $D / 2$ equals unity. The $K_{\mathrm{N}, \mathrm{UU}}$ values were obtained by processing the near notch tip FE results with a linear logarithm fit, Fig. 3. The fit was taken after selecting 
the maximum slope range along the local coordinate to avoid both the stress gradient drop, far from the notch, and the size effect of the elements at the tip. The fit stress slope was found to be in good agreement with the theoretical power law singularity deduced from the Williams' analysis.
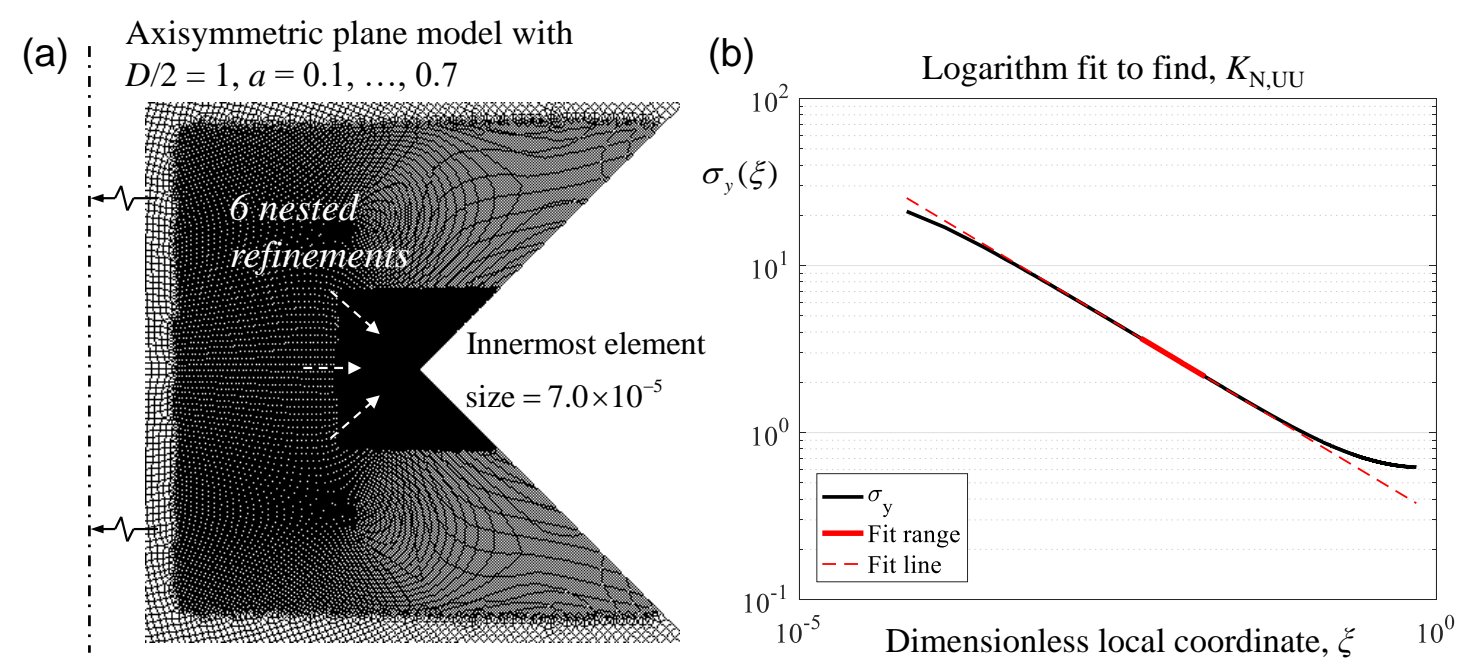

Figure 3: FE model to accurately find the unitary N-SIF: (a) FE mesh with multiple refinements at the notch tip, (b) N-SIF determination by means of optimized linear logarithm fit.

This dimensionless N-SIF only depends on the shape of the specimen, which is defined by the $\alpha$ angle and the notch depth ratio $a=A /(D / 2)$. When the notch depth is quite small, the role of the specimen size is limited, thus the deeper the notch, the higher the stress intensification. On the other hand, if the notch depth is large and comparable to the size of the diameter bar, the stress gradient is limited by the relatively near diametrically opposite side which experiences reverse stress gradient. Clearly, these two trends balance at an intermediate depth where the intensity factor is maximum (Fig. 4) and this agreed with the net stress concentration factor trend reported by Peterson's handbook for similar geometries [32]. The maximum N-SIF at the dimensionless notch depth $a=0.3$ is evident for both $\alpha=90^{\circ}$ and $\alpha=60^{\circ}$, Fig. 4. This optimal value for $a$ was then kept for the rounded notch, assuming that the configuration with the most dominant singular term provides a more developed gradient distribution in order to effectively evaluate the critical distance.

\subsection{Rounded V-notched specimen}

The FE model to find the stress distributions along the bisector of the rounded notch is shown in Fig. 5. A fine mesh was initially prepared over the entire geometry, then a series of three circular refinements were applied, thus obtaining an accurate stress simulation along the ligament section. The discretization of the output stress path was $1 \times 10^{-5}$ (referred to $D / 2=1$ ), which was then used for the dimensionless critical distance analysis developed in Section 3. The rounded notch FE analyses were only limited to the depth $a=0.3$ previously found as maximum N-SIF, thus the remaining geometry variable was the notch radius. The radius ratio parameter 


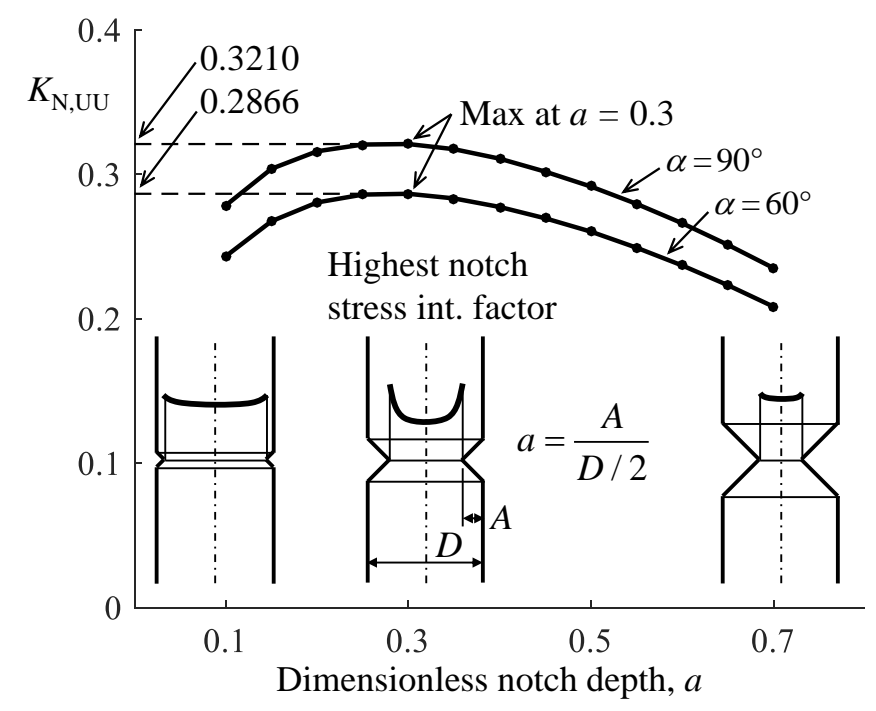

Figure 4: Dependence of the dimensionless N-SIF on the dimensionless depth for the notch angles $\alpha=90^{\circ}$ and $\alpha=60^{\circ}$.

$\rho=R / A=r / a$ was introduced and the series of values $\rho=0.01,0.02,0.05,0.1,0.2,0.5,1.0$ were analysed, which ranged over two orders of magnitude to cover all the possible configurations by a large margin.

Axisymmetric plane model with $D / 2=1$,

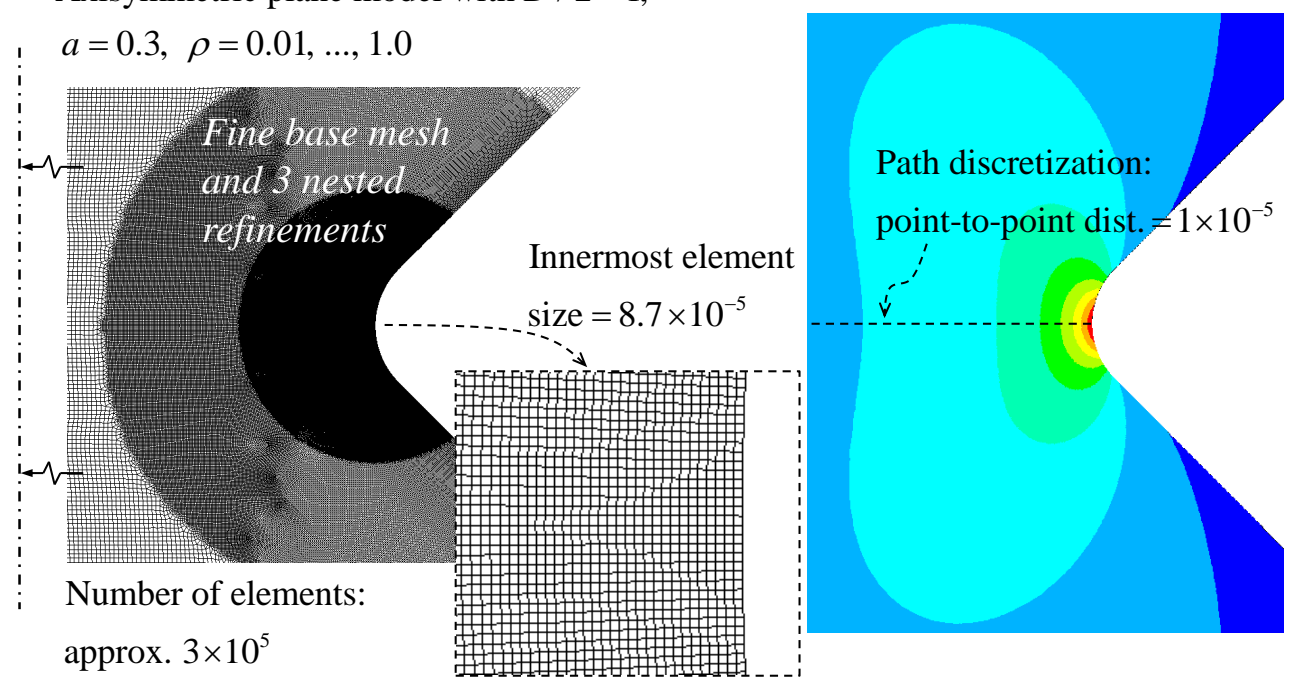

Figure 5: FE model to accurately find the axial stress distribution along the notch bisector of the rounded V-notched specimen.

The high resolution stress function $\sigma_{y}(\xi)$ obtained with the FE model, was then post-processed according to the LM and PM. The average stress was calculated by implementing the trapezoidal rule over the sample points along the bisector path, while the linear interpolation was used to evaluate the stress at a certain point on the same path. This numerical database was used to calculate the inversion functions (introduced in Section 3) which were then modelled to solve the inverse problem with accurate approximation, without the need to repeat the specific FE analysis for any single radius ratio value. 


\section{Critical distance determination}

\subsection{Line Method}

According to the LM formalization, the critical distance determination entails finding the $L$ value for which the average stress equals the fatigue limit. The LM average integral can be easily rewritten according to the dimensionless approach:

$$
\frac{1}{2 L} \int_{0}^{2 L} \Delta \sigma_{y}(x) \mathrm{d} x=\frac{1}{2 l} \int_{0}^{2 l} \Delta \sigma_{y}(\xi) \mathrm{d} \xi
$$

where $l=L /(D / 2)$ is defined in agreement with the other dimensionless sizes introduced above.

If only the stress distribution singular term is considered, the dimensionless N-SIF can be introduced and the average integral analytically solved:

$$
\frac{1}{2 l} \int_{0}^{2 l} \Delta \sigma_{\mathrm{N}} \frac{K_{\mathrm{N}, \mathrm{UU}}}{\xi^{s}} \mathrm{~d} \xi=\frac{\Delta \sigma_{\mathrm{N}}}{1-s} \frac{K_{\mathrm{N}, \mathrm{UU}}}{(2 l)^{s}}
$$

By imposing the average stress, calculated for the notched specimen fatigue limit, equal to the plain specimen fatigue limit, a simple equation follows:

$$
\frac{\Delta \sigma_{\mathrm{N}, \mathrm{fl}}}{1-s} \frac{K_{\mathrm{N}, \mathrm{UU}}}{\left(2 l_{0}\right)^{s}}=\Delta \sigma_{\mathrm{fl}}
$$

where $l_{0}$ is the (dimensionless) LM critical distance within the framework of the singular stress assumption. The fatigue stress concentration factor $K_{\mathrm{f}}=\Delta \sigma_{\mathrm{fl}} / \Delta \sigma_{\mathrm{N}, \mathrm{fl}}$ is then introduced:

$$
\frac{1}{1-s} \frac{K_{\mathrm{N}, \mathrm{UU}}}{\left(2 l_{0}\right)^{s}}=K_{\mathrm{f}}
$$

and this power equation can be easily reversed to find $l_{0}$ :

$$
l_{0}=\frac{1}{2}\left(\frac{K_{\mathrm{N}, \mathrm{UU}}}{(1-s) K_{\mathrm{f}}}\right)^{1 / s}
$$

Finally, the dimensional critical distance $L_{0}$ is obtained by multiplying it by the reference dimension $D / 2$ :

$$
L_{0}=\frac{D}{4}\left(\frac{K_{\mathrm{N}, \mathrm{UU}}}{(1-s) K_{\mathrm{f}}}\right)^{1 / s}
$$

The length $L_{0}$ can be regarded as a first approximation of the critical distance $L$ to be found, though not very accurate in some circumstances, as is evident in the example presented in Section 4.1.

When the notch radius $R$ is introduced, the stress distribution is bounded with a relatively severe gradient, in which the material critical distance needs to be compared. Two extreme conditions can result:

- the critical distance is much smaller than the notch radius, as a consequence the local stress gradient is not very high, Fig. 6 (a); 

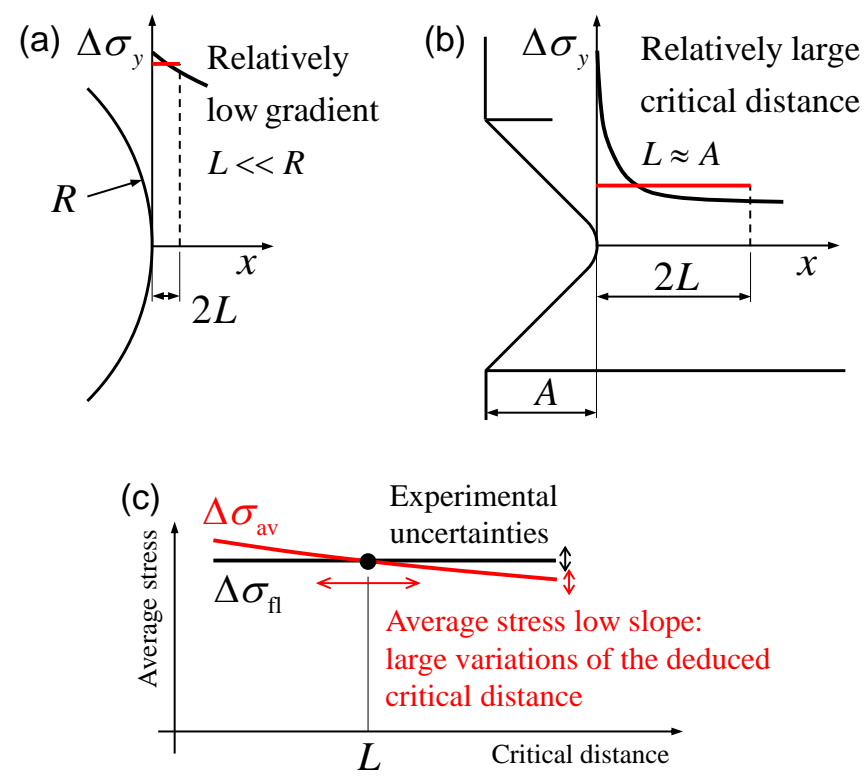

Figure 6: Extreme conditions for determining the critical distance: (a) small critical distance with respect to the local radius; (b) relatively large critical distance with respect to the notch depth; (c) inverse search uncertainty as a consequence of low gradient stress distribution.

- the critical distance is relatively too large, thus the integration length is partly outside the high gradient region, Fig. 6 (b).

Of these two cases, the latter can be obtained even with a (theoretical) perfectly sharp notch, since it is a comparison between the critical distance and the notch depth, while the former is specifically related to the rounded notch case. The accuracy of the inverse search is limited for both these situations. Indeed, a sizeable variation in the critical distance implies a small variation of the average stress, conversely, small variations in the fatigue limit stresses, due to any experimental bias, introduce a large deviation in the critical distance, Fig. 6 (c). For this reason, these two cases need to be identified by introducing two limit values, and the inverse search should be made in an intermediate range where the slope of the average stress is high.

The LM stress solution of a rounded notch, and its average integration according to the LM can still be computed according to an analytical form [33], including the effects of the local radius and the second non-singular term [34]. However, since the specific axisymmetric geometry of the V-notch on a relatively small diameter bar, an accurate solution can only be obtained with the FE modelling.

The approach followed here was to keep the singular form as a reference and then introduce a multiplicative correction function $f(l)$. The average stress integration can be rewritten as:

$$
\frac{1}{2 l} \int_{0}^{2 l} \Delta \sigma_{y}(\xi) \mathrm{d} \xi=\Delta \sigma_{\mathrm{N}} \frac{f(l)}{1-s} \frac{K_{\mathrm{N}, \mathrm{UU}}}{(2 l)^{s}}
$$

The function $f(l)$ tends to zero for a vanishingly small critical distance $l$. Therefore, this function was considered as an indicator to define the range limits for accurate inverse search. The minimum dimensionless critical distance 
was defined by fixing $f(l)$ equal to a certain fraction, and 0.5 was found to be an effective choice. When $f(l)$ is equal or smaller than 0.5 , the local radius of the notch is relatively too large, with respect to the critical distance, and the singular term is not predominant, Fig. 6 (a). On the other hand, if the critical distance is large, the stress distribution is characterized by a lower gradient, Fig. 6 (b), and the integration of the actual stress tends to go above the singular term, up to the condition of unitary correction function. The range $0.5 \leq f(l) \leq 1.0$ was therefore taken, and further modelling was confined within these limits. As an example, Fig. 7 reports the average stress for the notch radius ratio $\rho=0.1$ and $\alpha=90^{\circ}$, showing the determination of the minimum $l_{\min }$ and the maximum $l_{\max }$ dimensionless critical distances, corresponding to $f\left(l_{\min }\right)=0.5$ and $f\left(l_{\max }\right)=1.0$, respectively.

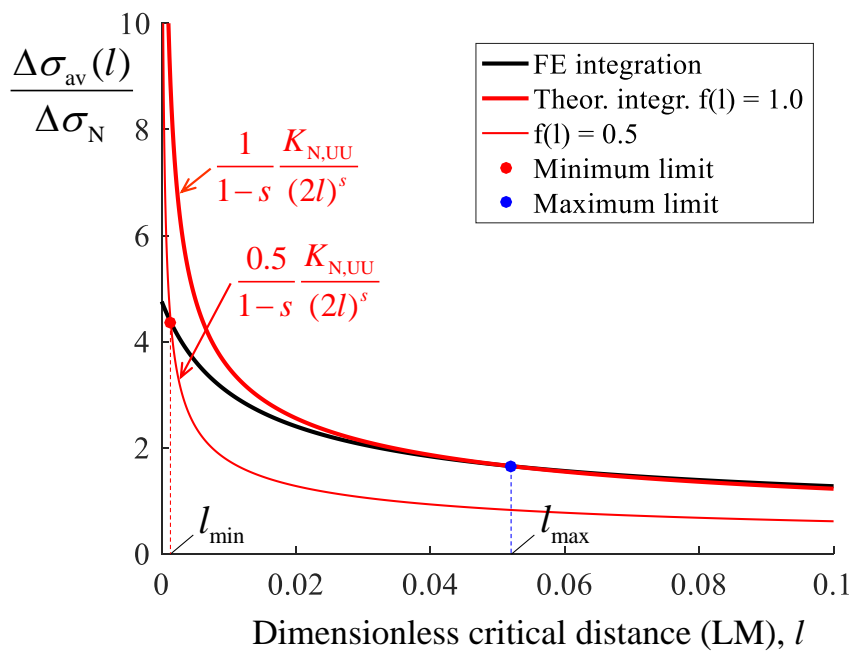

Figure 7: Limit values for determining the critical distance based on the correction function, example with $\alpha=90^{\circ}$ and $\rho=0.1$.

Similarly to above, after introducing the correction function, $l$ and $K_{\mathrm{f}}$ can be related:

$$
\frac{f(l)}{1-s} \frac{K_{\mathrm{N}, \mathrm{UU}}}{(2 l)^{s}}=K_{\mathrm{f}}
$$

and by substituting Eq. 8, a relationship between $l$ and $l_{0}$ is obtained:

$$
\frac{l}{f(l)^{1 / s}}=l_{0}
$$

An inversion function is finally defined as: $\gamma(l)=l / f(l)^{1 / s}$ to have the inverse problem simply formulated as:

$$
\gamma(l)=l_{0}
$$

In this equation critical distance $l$ is the unknown, while $l_{0}$ is the known term carrying the experimental information $K_{\mathrm{f}}$. Alternatively, $l_{0}$ can be seen as the first assessment value for $l$, which then has to be corrected by solving Eq. 14.

The dependence of this inversion function $\gamma(l)$ turned out to be very accurately approximated by a linear 
relationship, see for example Fig. 8 (a) for $\rho=0.1$. For this reason, the dimensionless critical distance was solved straightforwardly as a simple linear equation:

$$
l=l_{\min }+\frac{l_{0}-\gamma_{\min }}{\beta}
$$

where:

$$
\beta=\frac{\gamma_{\max }-\gamma_{\min }}{l_{\max }-l_{\min }}
$$

In principle, $\gamma_{\min }$ and $\gamma_{\max }$ are just the $\gamma$ values for $l_{\min }$ and $l_{\max }$, respectively. However, to recover small deviations from a straight line of the $\gamma(l)$ function, a weighted linear fit produced better results, especially for small $l$ values, instead of just connecting the maximum to the minimum points, Fig. 8 (b).
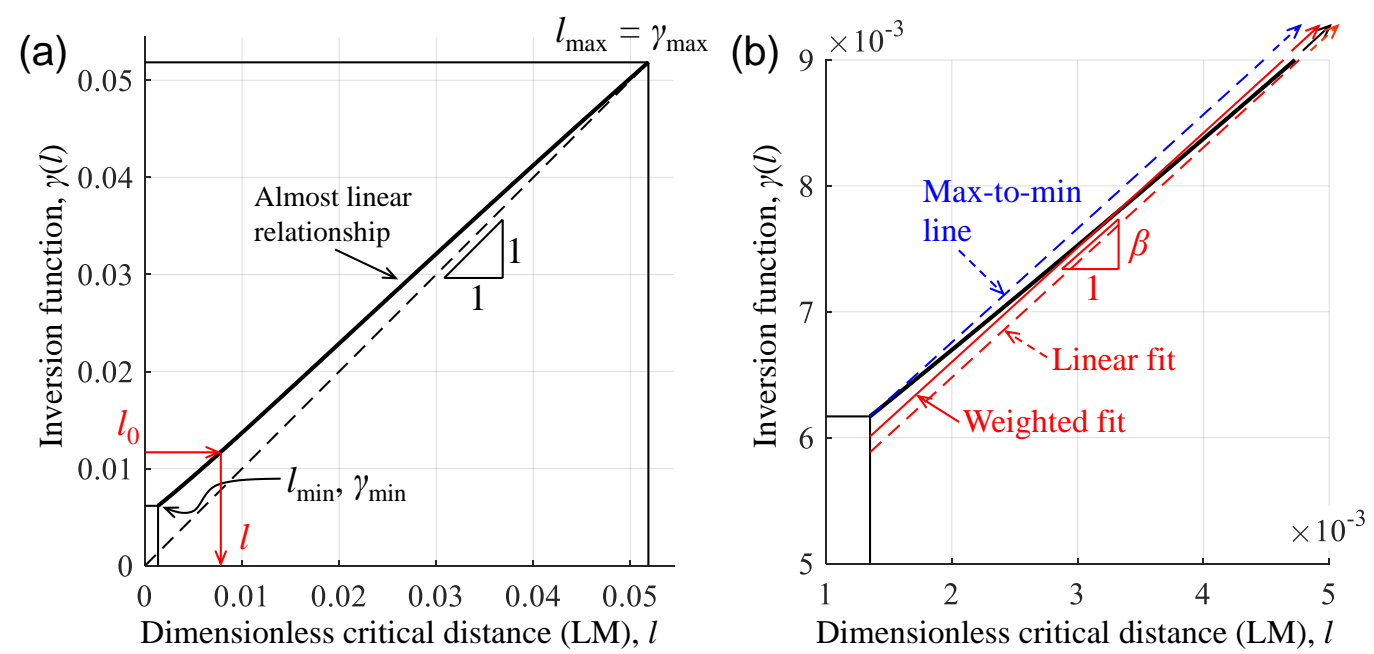

Figure 8: (a) LM inversion function and effective range boundaries. (b) Weighted linearisation for a more accurate fit especially for small dimensionless critical distances.

To have the limit values for $l$ and $\gamma$ as continuous functions of the radius ratio $\rho$, analytical fit models were selected and were accurate at least in the radius ratio range $\rho=0.01-1.0 . l_{\min }$ and $\gamma_{\min }$ were approximated with polynomials as follows:

$$
\begin{aligned}
& l_{\text {min }}=p_{1} \rho^{3}+p_{2} \rho^{2}+p_{3} \rho+p_{4} \\
& \gamma_{\text {min }}=q_{1} \rho^{3}+q_{2} \rho^{2}+q_{3} \rho+q_{4}
\end{aligned}
$$

whereas the identity $l_{\max }=\gamma_{\max }$, resulting from the maximum limit condition $f\left(l_{\max }\right)=1$ and Eq. 13 , gave a single equation for $l_{\max }$ and $\gamma_{\max }$ :

$$
l_{\max }=\gamma_{\max }=c_{1}+c_{2} \rho^{c_{3}}
$$

The coefficients for these models, about the notch angles $\alpha=90^{\circ}$ and $60^{\circ}$, are listed in Table 1 , with $\gamma_{\text {min }}$ derived by considering the weighted fit of the $\gamma(l)$ function. 
Table 1: $p_{i}, q_{i}, c_{i}$ fit model coefficients for the limit values of $l$ and $\gamma$.

\begin{tabular}{|c|c|c|c|c|}
\hline \multicolumn{5}{|c|}{ Notch angle $\alpha=90^{\circ}$, notch depth $a=0.3$, radius ratio range $\rho=0.01-1.0$} \\
\hline & $p_{1}, q_{1}, c_{1}$ & $p_{2}, q_{2}, c_{2}$ & $p_{3}, q_{3}, c_{3}$ & $p_{4}, q_{4}$ \\
\hline$l_{\min }$ & $1.5331595 \mathrm{E}-03$ & $-5.4476787 \mathrm{E}-03$ & 1.3930191E-02 & $4.3940341 \mathrm{E}-06$ \\
\hline$\gamma_{\min }$ & 4.3035219E-03 & $-2.0461370 \mathrm{E}-02$ & $6.2189732 \mathrm{E}-02$ & $-9.0345965 \mathrm{E}-06$ \\
\hline$l_{\max }$ & $-7.8790423 \mathrm{E}-02$ & $1.8286498 \mathrm{E}-01$ & $1.4527845 \mathrm{E}-01$ & \\
\hline \multicolumn{5}{|c|}{ Notch angle $\alpha=60^{\circ}$, notch depth $a=0.3$, radius ratio range $\rho=0.01-1.0$} \\
\hline & $p_{1}, q_{1}, c_{1}$ & $p_{2}, q$ & $p_{3}, q_{3}, c_{3}$ & $p_{4}, q_{4}$ \\
\hline$l_{\min }$ & $3.4760317 \mathrm{E}-03$ & $-1.0042167 \mathrm{E}-02$ & $1.8482608 \mathrm{E}-02$ & $1.3622097 \mathrm{E}-05$ \\
\hline$\gamma_{\min }$ & $1.2733490 \mathrm{E}-02$ & $-3.9007230 \mathrm{E}-02$ & 7.5860044E-02 & $1.0597477 \mathrm{E}-04$ \\
\hline$l_{\max }$ & $1.7783232 \mathrm{E}-02$ & $8.5788750 \mathrm{E}-02$ & 3.2189338E-01 & \\
\hline
\end{tabular}

The trends of the limit values are reported in Fig. 9 in logarithm scales. The minimum limit $l_{\min }$ and the corresponding $\gamma_{\min }$ strongly depend on the notch radius, indeed their variation is almost two orders of magnitude as $\rho$ ranges from 0.01 to 1.0 . On the other hand, the maximum limit $l_{\max }$ depends less on the radius since it is related to the stress distribution over a wider range of the notch region.

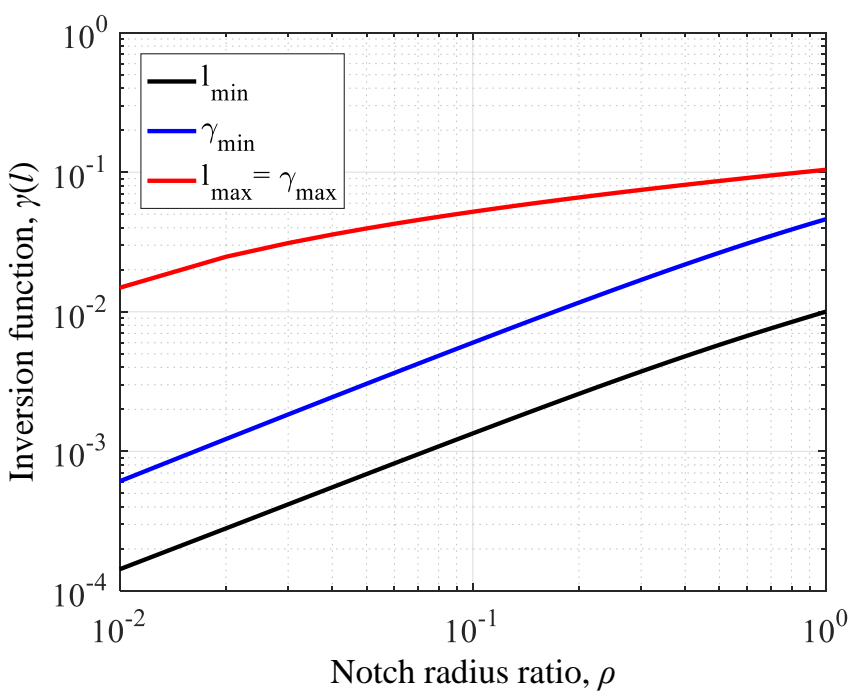

Figure 9: Trends of the $l$ and $\gamma$ limit values, for $\alpha=90^{\circ}$, in the investigated range of the radius ratio $\rho$.

\subsection{Point Method}

The determination of the critical distance according to the PM is presented in this section following the same steps as the determination with the LM. Initially, the point stress is analytically evaluated at half of the (dimensionless) critical distance position, only considering the singular term:

$$
\Delta \sigma_{\mathrm{N}, \mathrm{fl}} \frac{K_{\mathrm{N}, \mathrm{UU}}}{\left(l_{0}^{\prime} / 2\right)^{s}}=\Delta \sigma_{\mathrm{fl}}
$$

where $l_{0}^{\prime}$ is the PM counterpart of the previously defined $l_{0}$ for the LM. The fatigue stress concentration factor is 
then introduced and related to this length:

$$
\frac{K_{\mathrm{N}, \mathrm{UU}}}{\left(l_{0}^{\prime} / 2\right)^{s}}=K_{\mathrm{f}}
$$

and this equation can be solved for $l_{0}^{\prime}$ :

$$
l_{0}^{\prime}=2\left(\frac{K_{\mathrm{N}, \mathrm{UU}}}{K_{\mathrm{f}}}\right)^{1 / s}
$$

Finally, by multiplying for $D / 2$, the dimensional length $L_{0}^{\prime}$ is obtained:

$$
L_{0}^{\prime}=D\left(\frac{K_{\mathrm{N}, \mathrm{UU}}}{K_{\mathrm{f}}}\right)^{1 / s}
$$

This expression for $L_{0}^{\prime}$ is similar to the corresponding equation for the LM length $L_{0}$ (Eq. 10). Obviously, if the angle $\alpha$ were zero, the crack geometry would result which implies $s=0.5$, and then the LM and the PM singular term lengths would be equal: $L_{0}=L_{0}^{\prime}$. On the other hand, if $\alpha>0$ the PM value is slightly larger, and the relative difference is approximately $1.5 \%$ for $\alpha=60^{\circ}$ and $5 \%$ for $\alpha=90^{\circ}$.

A new correction function is introduced to take into account the actual stress distribution:

$$
\Delta \sigma_{\mathrm{N}, \mathrm{fl}} f^{\prime}\left(l^{\prime}\right) \frac{K_{\mathrm{N}, \mathrm{UU}}}{\left(l^{\prime} / 2\right)^{s}}=\Delta \sigma_{\mathrm{fl}}
$$

after introducing $K_{\mathrm{f}}$ and substituting Eq. 20, the same form as above for the inverse problem is obtained:

$$
\frac{l^{\prime}}{f\left(l^{\prime}\right)^{1 / s}}=l_{0}^{\prime}
$$

and the PM inversion function definition $\gamma^{\prime}\left(l^{\prime}\right)=l^{\prime} / f\left(l^{\prime}\right)^{1 / s}$ reduces the inverse search as:

$$
\gamma^{\prime}\left(l^{\prime}\right)=l_{0}^{\prime}
$$

Unlike the LM, the function $\gamma^{\prime}\left(l^{\prime}\right)$ is not linear, and 4th degree polynomial was found to provide an accurate approximation within the same $\mathrm{LM}$ range $\left(l_{\min }-l_{\max }\right)$ :

$$
l^{\prime}=\delta_{1} l_{0}^{4}+\delta_{2} l_{0}^{3}+\delta_{3} l_{0}^{\prime 2}+\delta_{4} l_{0}^{\prime}+\delta_{5}
$$

As an example, Fig. 10 shows the PM inversion function obtained by fitting the FE data for $\alpha=90^{\circ}$ and $\rho=0.1$. The $\delta_{i}$ coefficients depend in a complex way on the radius ratio. In order to make them available, these dependences are reported as tabular values in Tables 2 and 3 for $\alpha=90^{\circ}$ and $\alpha=60^{\circ}$, respectively. The Piecewise Cubic Hermite Interpolating Polynomial (PCHIP) was used to improve the resolution in terms of $\rho$. For example, the $\delta_{3}$ coefficient function for $\alpha=90^{\circ}$ is shown in Fig. 11, which reports both the reference FE values and the PCHIP which preserves the function shape and smoothly interpolates the reference points. 


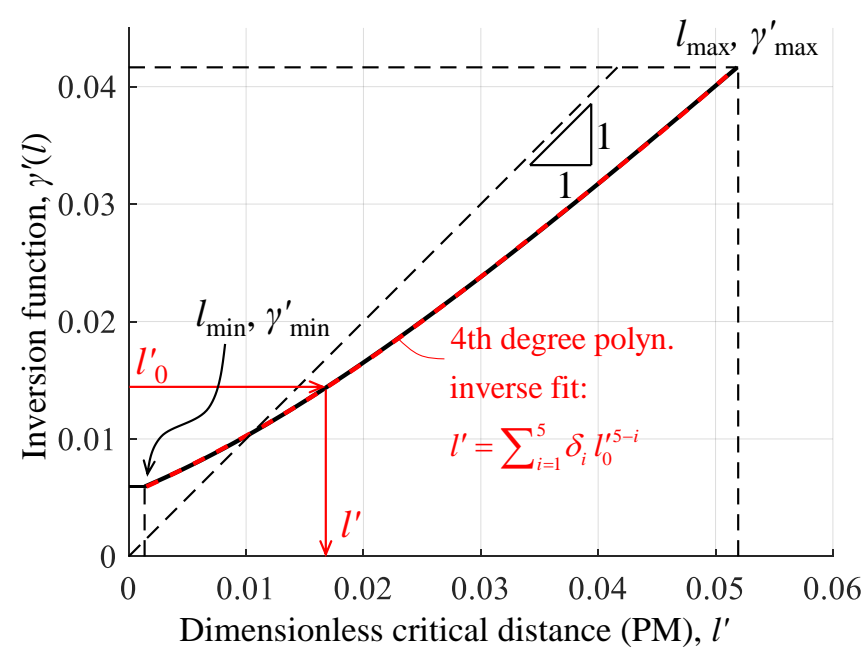

Figure 10: PM inversion function and 4th degree fit polynomial.

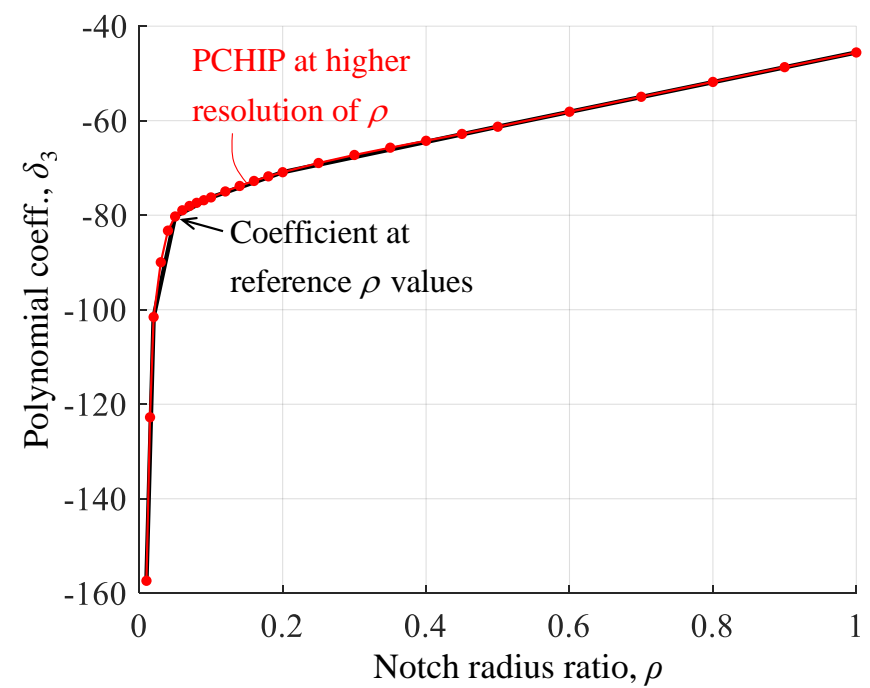

Figure 11: Example of a $\delta_{i}$ coefficient as a function of the radius ratio $\rho$, and higher resolution obtained with the PCHIP.

\section{Applications of the analytical procedure}

\subsection{LM and PM critical distance determination examples}

An example with realistic data is reported here to show in details the two calculation procedures according to the PM and the LM. The specimen dimensions are:

$$
D=20 \mathrm{~mm}, \quad \alpha=90^{\circ}, \quad A=3 \mathrm{~mm}, \quad R=0.2 \mathrm{~mm}, \quad \rho=0.0667
$$

and the notch singularity parameters for $\alpha=90^{\circ}$ (see Figs. 2 and 4), are:

$$
s=0.455516, \quad K_{\mathrm{N}, \mathrm{UU}}=0.3210
$$

The maximum and minimum dimensionless critical distance limits are obtained by means of Eqs. 17 and 18 along with the corresponding inversion function boundaries:

$$
l_{\min }=0.000909, \quad \gamma_{\min }=0.004047, \quad l_{\max }=\gamma_{\max }=0.04460
$$


Table 2: $\delta_{i}$ coefficients as function of the radius ratio $\rho, \alpha=90^{\circ}$.

\begin{tabular}{|c|c|c|c|c|c|}
\hline$\rho$ & $\delta_{1}$ & $\delta_{2}$ & $\delta_{3}$ & $\delta_{4}$ & $\delta_{5}$ \\
\hline 0.010 & $-4.0625068 \mathrm{E}+05$ & $1.3254291 \mathrm{E}+04$ & $-1.5735507 \mathrm{E}+02$ & $1.8756197 \mathrm{E}+00$ & $-8.3757643 \mathrm{E}-04$ \\
\hline 0.015 & $-2.0274357 \mathrm{E}+05$ & $8.0211209 E+03$ & $-1.2275768 \mathrm{E}+02$ & $1.9328524 \mathrm{E}+00$ & $-1.3066123 \mathrm{E}-03$ \\
\hline 0.020 & $-8.6517506 \mathrm{E}+04$ & $4.8921480 \mathrm{E}+03$ & $-1.0154513 \mathrm{E}+02$ & $1.9927558 \mathrm{E}+00$ & $-1.8215206 \mathrm{E}-03$ \\
\hline 0.030 & $-5.1291681 \mathrm{E}+04$ & $3.4643434 \mathrm{E}+03$ & $-8.9951601 \mathrm{E}+01$ & $2.1258786 \mathrm{E}+00$ & $-2.9992639 \mathrm{E}-03$ \\
\hline 0.040 & $-3.2578318 E+04$ & $2.6704605 \mathrm{E}+03$ & $-8.3263462 \mathrm{E}+01$ & $2.2659113 \mathrm{E}+00$ & $-4.3082657 E-03$ \\
\hline 0.050 & $-2.4660913 \mathrm{E}+04$ & $2.2881305 \mathrm{E}+03$ & $-8.0269106 \mathrm{E}+01$ & $2.3946781 \mathrm{E}+00$ & $-5.6862588 \mathrm{E}-03$ \\
\hline 0.060 & $-2.0805181 \mathrm{E}+04$ & $2.0693125 \mathrm{E}+03$ & $-7.8961946 \mathrm{E}+01$ & $2.5094271 \mathrm{E}+00$ & $-7.1198231 \mathrm{E}-03$ \\
\hline 0.070 & $-1.7944659 \mathrm{E}+04$ & $1.9052482 \mathrm{E}+03$ & $-7.8047904 \mathrm{E}+01$ & $2.6188123 \mathrm{E}+00$ & $-8.6244163 \mathrm{E}-03$ \\
\hline 0.080 & $-1.5864574 \mathrm{E}+04$ & $1.7824934 \mathrm{E}+03$ & $-7.7384144 \mathrm{E}+01$ & $2.7217664 \mathrm{E}+00$ & $-1.0181087 \mathrm{E}-02$ \\
\hline 0.090 & $-1.4350154 \mathrm{E}+04$ & $1.6876038 \mathrm{E}+03$ & $-7.6827827 \mathrm{E}+01$ & $2.8172221 \mathrm{E}+00$ & $-1.1770886 \mathrm{E}-02$ \\
\hline 0.100 & $-1.3186628 \mathrm{E}+04$ & $1.6071350 \mathrm{E}+03$ & $-7.6236117 \mathrm{E}+01$ & $2.9041121 \mathrm{E}+00$ & $-1.3374861 E-02$ \\
\hline 0.120 & $-1.1255252 \mathrm{E}+04$ & $1.4636002 \mathrm{E}+03$ & $-7.4974192 \mathrm{E}+01$ & $3.0619358 \mathrm{E}+00$ & $-1.6634614 \mathrm{E}-02$ \\
\hline 0.140 & $-9.6823246 E+03$ & $1.3428683 \mathrm{E}+03$ & $-7.3813836 \mathrm{E}+01$ & $3.2066934 \mathrm{E}+00$ & $-1.9981617 \mathrm{E}-02$ \\
\hline 0.160 & $-8.4416131 \mathrm{E}+03$ & $1.2433092 \mathrm{E}+03$ & $-7.2751063 \mathrm{E}+01$ & $3.3388229 \mathrm{E}+00$ & $-2.3395963 \mathrm{E}-02$ \\
\hline 0.180 & $-7.5068873 \mathrm{E}+03$ & $1.1632928 \mathrm{E}+03$ & $-7.1781887 \mathrm{E}+01$ & $3.4587621 \mathrm{E}+00$ & $-2.6857743 \mathrm{E}-02$ \\
\hline 0.200 & $-6.8519162 \mathrm{E}+03$ & $1.1011888 \mathrm{E}+03$ & $-7.0902322 \mathrm{E}+01$ & $3.5669490 \mathrm{E}+00$ & $-3.0347049 \mathrm{E}-02$ \\
\hline 0.250 & $-5.6654703 \mathrm{E}+03$ & $9.7870186 \mathrm{E}+02$ & $-6.8958378 \mathrm{E}+01$ & $3.8134532 \mathrm{E}+00$ & $-3.9212343 \mathrm{E}-02$ \\
\hline 0.300 & $-4.7055330 E+03$ & $8.7740106 \mathrm{E}+02$ & $-6.7254734 E+01$ & $4.0401526 \mathrm{E}+00$ & $-4.8277871 \mathrm{E}-02$ \\
\hline 0.350 & $-3.9424256 \mathrm{E}+03$ & $7.9384328 \mathrm{E}+02$ & $-6.5712999 \mathrm{E}+01$ & $4.2462522 \mathrm{E}+00$ & $-5.7471352 \mathrm{E}-02$ \\
\hline 0.400 & $-3.3464697 \mathrm{E}+03$ & $7.2458535 \mathrm{E}+02$ & $-6.4254782 E+01$ & $4.4309576 \mathrm{E}+00$ & $-6.6720508 \mathrm{E}-02$ \\
\hline 0.450 & $-2.8879867 \mathrm{E}+03$ & $6.6618413 \mathrm{E}+02$ & $-6.2801694 \mathrm{E}+01$ & $4.5934739 \mathrm{E}+00$ & $-7.5953057 \mathrm{E}-02$ \\
\hline 0.500 & $-2.5372980 \mathrm{E}+03$ & $6.1519647 \mathrm{E}+02$ & $-6.1275344 E+01$ & 4.7330064E+00 & $-8.5096720 \mathrm{E}-02$ \\
\hline 0.600 & $-1.9546400 \mathrm{E}+03$ & $5.1993752 \mathrm{E}+02$ & $-5.8103304 \mathrm{E}+01$ & $4.9827254 \mathrm{E}+00$ & $-1.0322669 \mathrm{E}-01$ \\
\hline 0.700 & $-1.4522507 \mathrm{E}+03$ & $4.3251698 \mathrm{E}+02$ & $-5.4944570 \mathrm{E}+01$ & $5.2118840 \mathrm{E}+00$ & $-1.2131309 \mathrm{E}-01$ \\
\hline 0.800 & $-1.0584000 \mathrm{E}+03$ & $3.5989780 \mathrm{E}+02$ & $-5.1800550 \mathrm{E}+01$ & $5.4071396 \mathrm{E}+00$ & $-1.3935146 \mathrm{E}-01$ \\
\hline 0.900 & $-8.0135821 \mathrm{E}+02$ & $3.0904295 \mathrm{E}+02$ & $-4.8672656 \mathrm{E}+01$ & $5.5551495 \mathrm{E}+00$ & $-1.5733732 \mathrm{E}-01$ \\
\hline 1.000 & $-7.0939535 \mathrm{E}+02$ & $2.8691538 \mathrm{E}+02$ & $-4.5562298 \mathrm{E}+01$ & $5.6425711 \mathrm{E}+00$ & $-1.7526620 \mathrm{E}-01$ \\
\hline
\end{tabular}

By multiplying for the reference dimension $D / 2$, the limits $L_{\min }$ and $L_{\max }$ are easily obtained:

$$
L_{\min }=(D / 2) l_{\min }=0.00909 \mathrm{~mm}, \quad L_{\max }=(D / 2) l_{\max }=0.4460 \mathrm{~mm}
$$

Assuming a value for $K_{\mathrm{f}}$ that is typical for a quite sharp notch and a high strength metal alloy, the singular term LM critical distance is then calculated with Eq. 9:

$$
K_{\mathrm{f}}=3.5, \quad l_{0}=0.01002
$$

The dimensionless critical distance $l$ can be obtained from Eq. 15 , and the final $L$ value is:

$$
l=0.00734, \quad L=(D / 2) l=0.0734 \mathrm{~mm}
$$

which falls well inside the range $L_{\min }-L_{\max }$.

Now this example with the same geometry and fatigue stress concentration factor input is repeated for the PM procedure. $l_{0}^{\prime}$ is calculated with Eq. 21 which gives a value similar to $l_{0}$ :

$$
K_{\mathrm{f}}=3.5, \quad l_{0}^{\prime}=0.01055
$$


Table 3: $\delta_{i}$ coefficients as function of the radius ratio $\rho, \alpha=60^{\circ}$.

\begin{tabular}{|c|c|c|c|c|c|}
\hline$\rho$ & $\delta_{1}$ & $\delta_{2}$ & $\delta_{3}$ & $\delta_{4}$ & $\delta_{5}$ \\
\hline 0.010 & $-1.0336805 \mathrm{E}+04$ & $9.2508401 \mathrm{E}+02$ & $-2.8841864 \mathrm{E}+01$ & $1.3658263 \mathrm{E}+00$ & $-3.6646815 \mathrm{E}-04$ \\
\hline 0.015 & $-1.1927899 \mathrm{E}+04$ & $1.1271447 \mathrm{E}+03$ & $-3.7532418 E+01$ & $1.5338756 \mathrm{E}+00$ & $-9.2141543 \mathrm{E}-04$ \\
\hline 0.020 & $-1.2744751 \mathrm{E}+04$ & $1.2499543 \mathrm{E}+03$ & $-4.3947712 \mathrm{E}+01$ & $1.6794386 \mathrm{E}+00$ & $-1.5289537 \mathrm{E}-03$ \\
\hline 0.030 & $-1.2565950 \mathrm{E}+04$ & $1.3152821 \mathrm{E}+03$ & $-5.1328805 \mathrm{E}+01$ & $1.9122292 \mathrm{E}+00$ & $-2.9184154 \mathrm{E}-03$ \\
\hline 0.040 & $-1.2155047 \mathrm{E}+04$ & $1.3533900 \mathrm{E}+03$ & $-5.6559601 \mathrm{E}+01$ & $2.1089337 \mathrm{E}+00$ & $-4.4575143 \mathrm{E}-03$ \\
\hline 0.050 & $-1.1700291 \mathrm{E}+04$ & $1.3657627 \mathrm{E}+03$ & $-5.9681694 \mathrm{E}+01$ & $2.2744973 \mathrm{E}+00$ & $-6.0599774 \mathrm{E}-03$ \\
\hline 0.060 & $-1.1225304 \mathrm{E}+04$ & $1.3564379 \mathrm{E}+03$ & $-6.1638299 E+01$ & $2.4183912 \mathrm{E}+00$ & $-7.7027882 \mathrm{E}-03$ \\
\hline 0.070 & $-1.0665461 \mathrm{E}+04$ & $1.3325856 \mathrm{E}+03$ & $-6.3296655 \mathrm{E}+01$ & $2.5479343 \mathrm{E}+00$ & $-9.4088204 \mathrm{E}-03$ \\
\hline 0.080 & $-1.0076647 \mathrm{E}+04$ & $1.3003888 \mathrm{E}+03$ & $-6.4584386 \mathrm{E}+01$ & $2.6648437 \mathrm{E}+00$ & $-1.1160636 \mathrm{E}-02$ \\
\hline 0.090 & $-9.5147424 E+03$ & $1.2660304 \mathrm{E}+03$ & $-6.5429116 E+01$ & $2.7708360 \mathrm{E}+00$ & $-1.2940796 \mathrm{E}-02$ \\
\hline 0.100 & $-9.0356311 \mathrm{E}+03$ & $1.2356935 \mathrm{E}+03$ & $-6.5758469 E+01$ & $2.8676282 \mathrm{E}+00$ & $-1.4731862 \mathrm{E}-02$ \\
\hline 0.120 & $-8.2132180 \mathrm{E}+03$ & $1.1802430 \mathrm{E}+03$ & $-6.5841784 \mathrm{E}+01$ & $3.0444486 \mathrm{E}+00$ & $-1.8356878 \mathrm{E}-02$ \\
\hline 0.140 & $-7.4418951 \mathrm{E}+03$ & $1.1217439 \mathrm{E}+03$ & $-6.5902954 \mathrm{E}+01$ & $3.2046141 \mathrm{E}+00$ & $-2.2055805 \mathrm{E}-02$ \\
\hline 0.160 & $-6.7510140 \mathrm{E}+03$ & $1.0643838 \mathrm{E}+03$ & $-6.5944067 \mathrm{E}+01$ & $3.3492680 \mathrm{E}+00$ & $-2.5808708 \mathrm{E}-02$ \\
\hline 0.180 & $-6.1699262 E+03$ & $1.0123503 \mathrm{E}+03$ & $-6.5967205 \mathrm{E}+01$ & $3.4795538 \mathrm{E}+00$ & $-2.9595649 \mathrm{E}-02$ \\
\hline 0.200 & $-5.7279831 E+03$ & $9.6983099 \mathrm{E}+02$ & $-6.5974454 \mathrm{E}+01$ & $3.5966148 \mathrm{E}+00$ & $-3.3396691 \mathrm{E}-02$ \\
\hline 0.250 & $-4.8892966 \mathrm{E}+03$ & $8.8451557 \mathrm{E}+02$ & $-6.5684501 \mathrm{E}+01$ & $3.8618732 \mathrm{E}+00$ & $-4.2994840 \mathrm{E}-02$ \\
\hline 0.300 & $-4.1787812 \mathrm{E}+03$ & 8.0963937E+02 & $-6.4911190 \mathrm{E}+01$ & $4.1036661 \mathrm{E}+00$ & $-5.2739827 \mathrm{E}-02$ \\
\hline 0.350 & $-3.5853512 E+03$ & 7.4405954E+02 & $-6.3799345 E+01$ & $4.3222430 \mathrm{E}+00$ & $-6.2568320 \mathrm{E}-02$ \\
\hline 0.400 & $-3.0979214 \mathrm{E}+03$ & $6.8663319 \mathrm{E}+02$ & $-6.2493791 E+01$ & $4.5178534 \mathrm{E}+00$ & $-7.2416987 \mathrm{E}-02$ \\
\hline 0.450 & $-2.7054060 \mathrm{E}+03$ & $6.3621745 \mathrm{E}+02$ & $-6.1139352 \mathrm{E}+01$ & $4.6907467 \mathrm{E}+00$ & $-8.2222494 \mathrm{E}-02$ \\
\hline 0.500 & $-2.3967197 E+03$ & $5.9166945 \mathrm{E}+02$ & $-5.9880852 E+01$ & $4.8411724 \mathrm{E}+00$ & $-9.1921509 \mathrm{E}-02$ \\
\hline 0.600 & $-1.8753865 E+03$ & $5.0964919 \mathrm{E}+02$ & $-5.7461307 \mathrm{E}+01$ & $5.1130966 \mathrm{E}+00$ & $-1.1111942 \mathrm{E}-01$ \\
\hline 0.700 & $-1.4144811 \mathrm{E}+03$ & $4.3434980 \mathrm{E}+02$ & $-5.4851063 \mathrm{E}+01$ & $5.3628133 \mathrm{E}+00$ & $-1.3020646 \mathrm{E}-01$ \\
\hline 0.800 & $-1.0458429 \mathrm{E}+03$ & $3.6994290 \mathrm{E}+02$ & $-5.2049173 E+01$ & $5.5768889 \mathrm{E}+00$ & $-1.4917055 \mathrm{E}-01$ \\
\hline 0.900 & $-8.0131109 \mathrm{E}+02$ & $3.2060010 \mathrm{E}+02$ & $-4.9054690 \mathrm{E}+01$ & $5.7418898 \mathrm{E}+00$ & $-1.6799960 \mathrm{E}-01$ \\
\hline 1.000 & $-7.1272509 \mathrm{E}+02$ & $2.9049302 \mathrm{E}+02$ & $-4.5866667 \mathrm{E}+01$ & $5.8443823 \mathrm{E}+00$ & $-1.8668153 \mathrm{E}-01$ \\
\hline
\end{tabular}

From Table $2\left(\alpha=90^{\circ}\right)$, by linearly interpolating $\rho=0.0667$ between the two tabular values $\rho=0.060$ and $\rho=0.070$, the $\delta_{i}$ coefficients are obtained:

$$
\begin{aligned}
& \delta_{1}=-1.88982 \times 10^{4}, \quad \delta_{2}=1.95994 \times 10^{3}, \quad \delta_{3}=-7.83526 \times 10^{1}, \\
& \delta_{4}=2.58235, \quad \delta_{5}=-8.12289 \times 10^{-3}
\end{aligned}
$$

The PM dimensionless critical distance is calculated with Eq. 26 and the final $L^{\prime}$ value is:

$$
l^{\prime}=0.01247, \quad L^{\prime}=(D / 2) l^{\prime}=0.1247 \mathrm{~mm}
$$

These two inverse searches are reported in Fig. 12 which highlights that, despite the similar $l_{0}$ and $l_{0}^{\prime}$ values, the relative difference between LM and PM critical distances can be considerable, at least for this combination of input values.

\subsection{Inverse search validation}

The proposed critical distance determination procedure was validated with a series of numerical cases in which the average stress (LM) and the point stress (PM) were back-calculated by post-processing the results of full scale FE models, exploring different combinations of the geometry parameters. The first of these simulations 


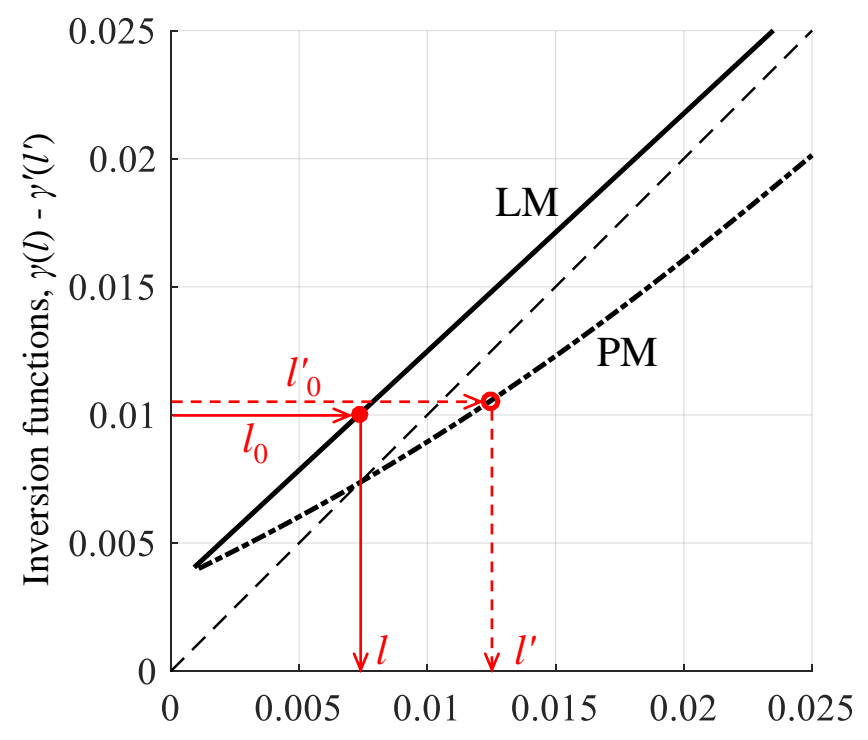

LM and PM dimensionless critical distances, $l-l^{\prime}$

Figure 12: Inverse search example and comparison between the critical distances obtained with the LM and the PM.

regarded the previous example and the calculated stresses are reported in Fig. 13 where the PM and the LM stresses are in evident agreement with the reference stress. All the results of the analysed validation cases are listed in Table 4. The errors with respect to the reference stress were always below $1 \%$.

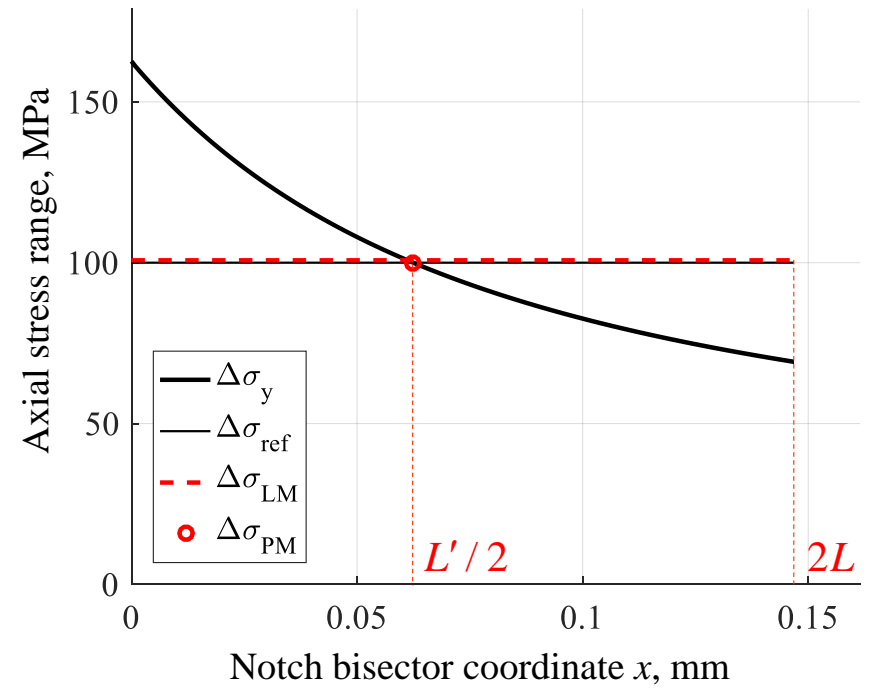

Figure 13: LM and PM back-calculated stresses and comparison with the reference stress.

This analysis confirmed the high accuracy of the proposed calculation, at least for the geometrical dimensions considered here. Nevertheless, there is some inaccuracy with extremely low $l$ values, and consequently very small $\rho$, which are, however, unrealistic for most of the engineering materials. 
Table 4: Successful validation analysis, small stress percentage errors obtained for different parameter combinations.

\begin{tabular}{ll|ll|ll}
\hline Test n. 1 & $\alpha=90^{\circ}$ & Test n. 2 & $\alpha=90^{\circ}$ & Test n. 3 & $\alpha=90^{\circ}$ \\
$R=0.2 \mathrm{~mm}$ & $K_{\mathrm{f}}=3.5$ & $R=0.2 \mathrm{~mm}$ & $K_{\mathrm{f}}=4.2$ & $R=0.2 \mathrm{~mm}$ & $K_{\mathrm{f}}=4.9$ \\
$L=0.0734 \mathrm{~mm}$ & $L^{\prime}=0.1247 \mathrm{~mm}$ & $L=0.0378 \mathrm{~mm}$ & $L^{\prime}=0.0686 \mathrm{~mm}$ & $L=0.0171 \mathrm{~mm}$ & $L^{\prime}=0.0314 \mathrm{~mm}$ \\
LM err. $0.74 \%$ & PM err. $0.06 \%$ & LM err. $0.60 \%$ & PM err. 0.34\% & LM err. $-0.42 \%$ & PM err. $-0.001 \%$ \\
\hline Test n. 4 & $\alpha=90^{\circ}$ & Test n. 5 & $\alpha=90^{\circ}$ & Test n. 6 & $\alpha=90^{\circ}$ \\
$R=1.0 \mathrm{~mm}$ & $K_{\mathrm{f}}=1.7$ & $R=1.0 \mathrm{~mm}$ & $K_{\mathrm{f}}=2.5$ & $R=1.0 \mathrm{~mm}$ & $K_{\mathrm{f}}=2.6$ \\
$L=0.4190 \mathrm{~mm}$ & $L^{\prime}=0.6779 \mathrm{~mm}$ & $L=0.070 \mathrm{~mm}$ & $L^{\prime}=0.134 \mathrm{~mm}$ & $L=0.049 \mathrm{~mm}$ & $L^{\prime}=0.092 \mathrm{~mm}$ \\
LM err. $-0.18 \%$ & PM err. $-0.08 \%$ & LM err. $-0.04 \%$ & PM err. $0.03 \%$ & LM err. $-0.25 \%$ & PM err. $0.03 \%$ \\
\hline Test n. 7 & $\alpha=60^{\circ}$ & Test n. 8 & $\alpha=60^{\circ}$ & Test n. 9 & $\alpha=60^{\circ}$ \\
$R=0.2 \mathrm{~mm}$ & $K_{\mathrm{f}}=3.5$ & $R=0.2 \mathrm{~mm}$ & $K_{\mathrm{f}}=4.2$ & $R=0.2 \mathrm{~mm}$ & $K_{\mathrm{f}}=5.2$ \\
$L=0.084 \mathrm{~mm}$ & $L^{\prime}=0.140 \mathrm{~mm}$ & $L=0.045 \mathrm{~mm}$ & $L^{\prime}=0.081 \mathrm{~mm}$ & $L=0.014 \mathrm{~mm}$ & $L^{\prime}=0.028 \mathrm{~mm}$ \\
LM err. $0.37 \%$ & PM err. $-0.11 \%$ & LM err. $0.66 \%$ & PM err. $0.23 \%$ & LM err. $-0.06 \%$ & PM err. $-0.45 \%$ \\
\hline Test n. 10 & $\alpha=60^{\circ}$ & Test n. 11 & $\alpha=60^{\circ}$ & Test n. 12 & $\alpha=60^{\circ}$ \\
$R=1.0 \mathrm{~mm}$ & $K_{\mathrm{f}}=1.7$ & $R=1.0 \mathrm{~mm}$ & $K_{\mathrm{f}}=2.3$ & $R=1.0 \mathrm{~mm}$ & $K_{\mathrm{f}}=2.5$ \\
$L=0.435 \mathrm{~mm}$ & $L^{\prime}=0.682 \mathrm{~mm}$ & $L=0.130 \mathrm{~mm}$ & $L^{\prime}=0.238 \mathrm{~mm}$ & $L=0.074 \mathrm{~mm}$ & $L^{\prime}=0.141 \mathrm{~mm}$ \\
LM err. $-0.54 \%$ & PM err. $0.72 \%$ & LM err. $0.19 \%$ & PM err. $0.34 \%$ & LM err. $0.29 \%$ & PM err. $0.29 \%$
\end{tabular}

\subsection{Sensitivity to the experimental input}

The proposed LM and PM inversion procedures provide the relationship between the experimental input $K_{\mathrm{f}}$ and the critical distance output $L$ or $L^{\prime}$. The sensitivity analysis presented here quantifies how the inverse search result is affected by a variation of the input, e.g. due to any experimental issues or as a result of the nonhomogeneity of the material. Considering the example reported in Section 4.1, and assuming a small alteration of $K_{\mathrm{f}}$, such as $\Delta K_{\mathrm{f}}=0.1$, the LM and PM critical distance variations are:

$$
\begin{aligned}
& L=0.0734 \mathrm{~mm}, \quad \Delta L=-0.0065 \mathrm{~mm} \\
& L^{\prime}=0.1247 \mathrm{~mm}, \quad \Delta L^{\prime}=-0.0096 \mathrm{~mm}
\end{aligned}
$$

These variations have more significance if related to the size of the critical distances themselves and the entity of the input alteration. Rather than the finite difference ratios, the derivatives are considered, giving the following sensitivity definitions:

$$
S=-\frac{1}{L} \frac{\mathrm{d} L}{\mathrm{~d} K_{\mathrm{f}}}=-\frac{1}{l} \frac{\mathrm{d} l}{\mathrm{~d} K_{\mathrm{f}}}, \quad S^{\prime}=-\frac{1}{L^{\prime}} \frac{\mathrm{d} L^{\prime}}{\mathrm{d} K_{\mathrm{f}}}=-\frac{1}{l^{\prime}} \frac{\mathrm{d} l^{\prime}}{\mathrm{d} K_{\mathrm{f}}}
$$

In principle, these sensitivity functions could be analytically calculated by combining the equations reported above. However, in order to avoid heavy calculations, a numerical analysis was implemented. LM and PM sensitivity graphs are shown in Fig. 14 for the entire $\rho$ range investigated. The graphs highlight that the lower the radius ratio $\rho$, the lower the sensitivity, especially for small critical distance values. This always happens for the LM, while for the PM some of the lower $\rho$ lines can be slightly above the higher $\rho$ lines, but only for large critical distances. Considering a certain specimen geometry, i.e. by following a single $\rho$ line, there is a minimum sensitivity which can be interpreted as an optimal configuration. At the lateral extremes, the higher sensitivity can be explained by the two conditions of Fig. 6 (a) and (b) which are the cases of excessively small or overly large 
critical distances, respectively. This evidence confirmed that $L_{\min }-L_{\max }$ is the effective range for an accurate inverse search where the sensitivity to bias is small. Therefore, the critical distance result obtained should be well inside this range. If not, the experimental fatigue series should be repeated with a revised specimen geometry. A smaller notch radius is required for a low critical distance, while a higher diameter specimen is recommended for a large critical distance. On the other hand, if a preliminary guess value is available, e.g. from the literature or other tests, the availability of $L_{\min }$ and $L_{\max }$ means that the notched specimen can be sized correctly.
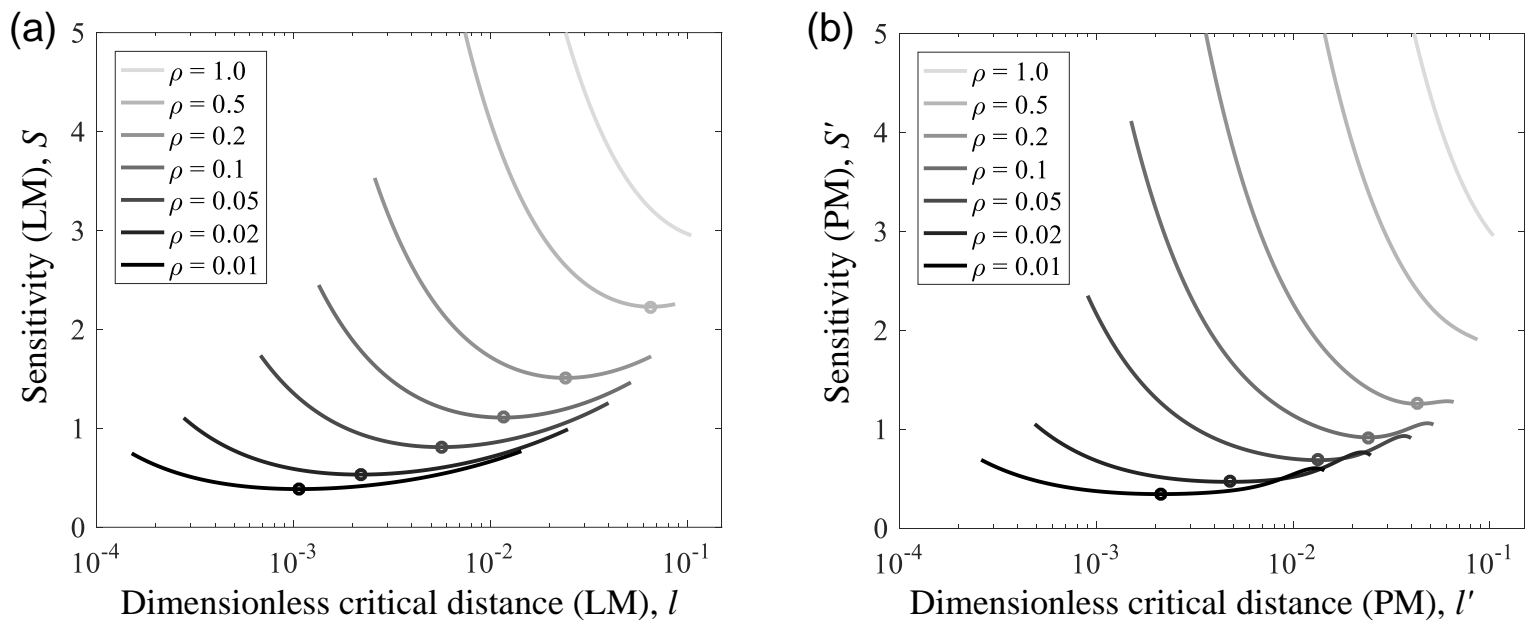

Figure 14: Sensitivity functions of the critical distance determination for: (a) LM and (b) PM.

\subsection{Direct problem}

Besides the inverse search, in which the critical distance is the unknown, the proposed analytical procedure can be used to solve the "direct" problem, where the critical distance is known (or assumed as known) and the specimen fatigue stress concentration factor is assessed. For example, this is useful for a preliminary evaluation of the loads for the notched specimen fatigue test series, at least to have a starting point.

The direct problem can be solved straightforwardly for the LM, since the relationship between the variables $l$ and $l_{0}$ just linear. $l_{0}$ is initially found from $l$ :

$$
l_{0}=\gamma_{\min }+\beta\left(l-l_{\min }\right)
$$

and then $K_{\mathrm{f}}$ is derived from $l_{0}$ with Eq. 8 .

The PM derivation of $l_{0}^{\prime}$ from $l^{\prime}$ is more challenging since it has a 4th degree polynomial which cannot be easily inverted, though analytically possible. An iterative procedure is suggested here. After having verified that $l^{\prime}$ falls in the range $l_{\min }-l_{\max }$, the average of these two values is assumed as the first guess value for $l_{0}^{\prime}$ :

$$
l_{0,1}^{\prime}=\left(l_{\max }+l_{\min }\right) / 2
$$


and the corresponding $l_{1}^{\prime}$ is obtained from Eq. 26. If $l_{1}^{\prime}>l^{\prime}$ the guess value needs to be decreased, otherwise increased. A small increase or decrease quantity is suggested, such as 0.001 , and then the guess value is updated:

$$
\begin{array}{ll}
l_{0,2}^{\prime}=l_{0,1}^{\prime}-0.001 & \text { if } l_{1}^{\prime}>l^{\prime} \\
l_{0,2}^{\prime}=l_{0,1}^{\prime}+0.001 & \text { if } l_{1}^{\prime}<l^{\prime}
\end{array}
$$

This updating has to be repeated until the inequality check reverses at the $n$-th iteration, thus obtaining:

$$
l_{n}^{\prime}>l^{\prime}>l_{n-1}^{\prime} \quad \text { or } \quad l_{n}^{\prime}<l^{\prime}<l_{n-1}^{\prime}
$$

A local linearisation, such as for the LM as shown in Fig. 15, is sufficiently accurate since the suggested step quite small, and the last iteration value can be easily found:

$$
l_{0, n+1}^{\prime}=l_{0, \mathrm{n}}^{\prime}+\frac{l_{0, n-1}^{\prime}-l_{0, n}^{\prime}}{l_{n-1}^{\prime}-l_{n}^{\prime}}\left(l^{\prime}-l_{n}^{\prime}\right)
$$

Finally, $K_{\mathrm{f}}$ is obtained with Eq. 20 introducing $l_{0, n+1}^{\prime}$ as an accurate approximation of $l_{0}^{\prime}$. With regard to the example at the beginning of this section, $K_{\mathrm{f}}=3.4995$ was found with this iterative procedure which is very similar to the reference value $K_{\mathrm{f}}=3.5$.

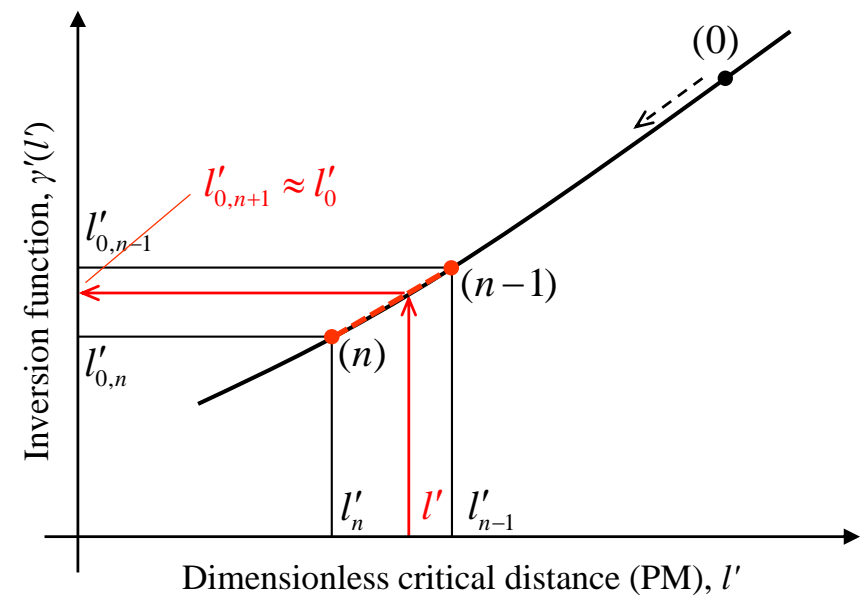

Figure 15: Numerical iterative procedure suggested for the PM direct problem.

\section{Conclusions}

In this paper, a small radius V-notched specimen has been presented as an alternative to the crack threshold stress intensity factor for determining the fatigue critical distance, and a calculation procedure is provided to avoid the specific FE simulation of the specimen. The present analysis was formulated as dimensionless where the fatigue stress concentration factor (the experimental input) was initially converted into a preliminary critical distance value, based on the singular stress term, and the definitive length is then obtained as the solution of an inverse problem. This inversion turned out to be linear with the Line Method, while a 4th degree polynomial was 
required for the Point Method. A series of validation tests confirmed the accuracy of the analytical modelling and the coefficients provided. By means of a specific definition of a sensitivity parameter, it was shown how the obtained critical distance value should fall in a certain range to avoid an ill-posed inverse problem. If the material critical distance is expected to be relatively small, the notch radius has to be sharp as well. On the other hand, if the critical distance is high, the specimen size should be large accordingly. Numerical examples with typical values for structural metals were presented in order to show step-by-step the application of this analytical procedure. Though not reported in this paper, an experimental activity is being performed and the results will be available in future publications.

The same approach can be applied to other critical distance formalizations, such as the Area or the Volume Methods, or even to a multiaxial criterion combined for example with the Point method, to accurately provide the specific length. The steps to follow are the same: put the problem in a dimensionless form, derive the length as based on the singular term, define and calculate the inversion function, and model its dependence on the radius ratio.

This study has only investigated calculating the critical distance in the case of fatigue loading. In principle, the same specimen and procedure could equally be used for the monotonic fracture critical distance. However, the inherent strength $\sigma_{0}$ should either be equal to the ultimate tensile strength (e.g. for brittle materials) or at least known from another test. With $\sigma_{0}$ available, the fatigue stress concentration factor $K_{\mathrm{f}}$ can simply be replaced by the ratio between the material inherent strength and the notched specimen nominal stress at fracture. On the hand, if the inherent strength is unknown, this procedure cannot be applied since two notched specimens are required with different levels of sharpness.

\section{Acknowledgments}

This work was supported by the University of Pisa under the "PRA - Progetti di Ricerca di Ateneo" (Institutional Research Grants) - Project No. PRA_2016_36.

\section{References}

[1] D. Taylor, The Theory of Critical Distances: A New Perspective in Fracture Mechanics, Elsevier Science, 2007, ISBN: 9780080444789.

[2] D. Taylor, The theory of critical distances, Engineering Fracture Mechanics 75 (7) (2008) 1696-1705. doi:10.1016/j.engfracmech.2007.04.007.

[3] D. Taylor, G. Wang, The validation of some methods of notch fatigue analysis, Fatigue and Fracture of Engineering Materials and Structures 23 (5) (2000) 387-394.

[4] X.-Y. Liu, T.-X. Su, Y. Zhang, M.-N. Yuan, A multiaxial high-cycle fatigue life evaluation model for notched structural components, International Journal of Fatigue 80 (2015) 443-448. doi:10.1016/j.ijfatigue.2015.07.010.

[5] L. Susmel, A unifying approach to estimate the high-cycle fatigue strength of notched components subjected to both uniaxial and multiaxial cyclic loadings, Fatigue and Fracture of Engineering Materials and Structures 27 (5) (2004) 391-411. doi:10.1111/j.14602695.2004.00759.x. 
[6] C. Santus, Fretting fatigue of aluminum alloy in contact with steel in oil drill pipe connections, modeling to interpret test results, International Journal of Fatigue 30 (4) (2008) 677-688. doi:10.1016/j.ijfatigue.2007.05.006.

[7] L. Bertini, C. Santus, Fretting fatigue tests on shrink-fit specimens and investigations into the strength enhancement induced by deep rolling, International Journal of Fatigue 81 (2015) 179-190. doi:10.1016/j.ijfatigue.2015.08.007.

[8] J. Araújo, F. Castro, S. Pommier, J. Bellecave, J. Meriaux, On the design and test of equivalent configurations for notch and fretting fatigue, Fatigue and Fracture of Engineering Materials and Structures 39 (10) (2016) 1241-1250. doi:10.1111/ffe.12435.

[9] J. Araújo, L. Susmel, M. Pires, F. Castro, A multiaxial stress-based critical distance methodology to estimate fretting fatigue life, Tribology International 108 (2017) 2-6. doi:10.1016/j.triboint.2016.07.028.

[10] J. Araújo, G. Almeida, J. Ferreira, C. da Silva, F. Castro, Early cracking orientation under high stress gradients: The fretting case, International Journal of Fatigue 100 (2017) 611-618. doi:10.1016/j.ijfatigue.2016.12.013.

[11] C. Ronchei, A. Carpinteri, G. Fortese, D. Scorza, S. Vantadori, Fretting High-Cycle Fatigue Assessment through a Multiaxial Critical Plane-Based Criterion in Conjunction with the Taylor's Point Method, Solid State Phenomena 258 (2017) 217-220. doi:10.4028/www.scientific.net/SSP.258.217.

[12] S. Vantadori, G. Fortese, C. Ronchei, D. Scorza, A stress gradient approach for fretting fatigue assessment of metallic structural components, International Journal of Fatigue 101 (2017) 1-8. doi:10.1016/j.ijfatigue.2017.04.004.

[13] M. Benedetti, V. Fontanari, C. Santus, M. Bandini, Notch fatigue behaviour of shot peened high-strength aluminium alloys: Experiments and predictions using a critical distance method, International Journal of Fatigue 32 (10) (2010) 1600-1611. doi:10.1016/j.ijfatigue.2010.02.012.

[14] M. Benedetti, V. Fontanari, M. Allahkarami, J. Hanan, M. Bandini, On the combination of the critical distance theory with a multiaxial fatigue criterion for predicting the fatigue strength of notched and plain shot-peened parts, International Journal of Fatigue 93 (2016) 133-147. doi:10.1016/j.ijfatigue.2016.08.015.

[15] R. Tovo, P. Livieri, An implicit gradient application to fatigue of sharp notches and weldments, Engineering Fracture Mechanics 74 (4) (2007) 515-526. doi:10.1016/j.engfracmech.2006.06.009.

[16] L. Susmel, H. Askes, T. Bennett, D. Taylor, Theory of Critical Distances versus Gradient Mechanics in modelling the transition from the short to long crack regime at the fatigue limit, Fatigue and Fracture of Engineering Materials and Structures 36 (9) (2013) 861-869. doi:10.1111/ffe.12066.

[17] C. Bagni, H. Askes, L. Susmel, Gradient elasticity: a transformative stress analysis tool to design notched components against uniaxial/multiaxial high-cycle fatigue, Fatigue and Fracture of Engineering Materials and Structures 39 (8) (2016) 1012-1029. doi:10.1111/ffe.12447.

[18] C. Bagni, H. Askes, E. Aifantis, Gradient-enriched finite element methodology for axisymmetric problems, Acta Mechanica 228 (4) (2017) 1423-1444. doi:10.1007/s00707-016-1762-7.

[19] Standard Test Method for Measurement of Fatigue Crack Growth Rates, ASTM E647 - 15 (2015). doi:10.1520/E0647-15.

[20] W. Li, L. Susmel, H. Askes, F. Liao, T. Zhou, Assessing the integrity of steel structural components with stress raisers using the Theory of Critical Distances, Engineering Failure Analysis 70 (2016) 73-89. doi:10.1016/j.engfailanal.2016.07.007.

[21] T. Yin, A. Tyas, O. Plekhov, A. Terekhina, L. Susmel, A novel reformulation of the Theory of Critical Distances to design notched metals against dynamic loading, Materials and Design 69 (2015) 197-212. doi:10.1016/j.matdes.2014.12.026.

[22] S. Cicero, V. Madrazo, I. Carrascal, On the Point Method load-bearing capacity predictions in A17075-T651 structural components containing stress risers, Engineering Failure Analysis 26 (2012) 129-138. doi:10.1016/j.engfailanal.2012.07.008.

[23] T. Voiconi, R. Negru, E. Linul, L. Marsavina, H. Filipescu, The notch effect on fracture of polyurethane materials, Frattura ed Integrità Strutturale 30 (2014) 101-108. doi:10.3221/igf-esis.30.14.

[24] L. Susmel, D. Taylor, The Theory of Critical Distances as an alternative experimental strategy for the determination of KIc and $\Delta$ Kth, Engineering Fracture Mechanics 77 (9) (2010) 1492-1501. doi:10.1016/j.engfracmech.2010.04.016.

[25] L. Susmel, D. Taylor, The theory of critical distances to estimate finite lifetime of notched components subjected to constant and variable amplitude torsional loading, Engineering Fracture Mechanics 98 (1) (2013) 64-79. doi:10.1016/j.engfracmech.2012.12.007.

[26] D. Taylor, Applications of the theory of critical distances in failure analysis, Engineering Failure Analysis 18 (2) (2011) $543-549$. doi:10.1016/j.engfailanal.2010.07.002.

[27] A. Campagnolo, G. Meneghetti, F. Berto, K. Tanaka, Crack initiation life in notched steel bars under torsional fatigue: Synthesis based on the averaged strain energy density approach, International Journal of Fatigue 100 (2017) 563-574. doi:10.1016/j.ijfatigue.2016.12.022.

[28] F. Berto, A. Campagnolo, P. Lazzarin, Fatigue strength of severely notched specimens made of Ti-6Al-4V under multiaxial loading, Fatigue and Fracture of Engineering Materials and Structures 38 (5) (2015) 503-517. doi:10.1111/ffe.12272.

[29] M. Williams, Stress Singularities Resulting From Various Boundary Conditions in Angular Corners of Plates in Extension, Journal of Applied Mechanics, Transactions ASME 19 (1952) 526-528.

[30] B. Atzori, P. Lazzarin, G. Meneghetti, A unified treatment of the mode I fatigue limit of components containing notches or defects, International Journal of Fracture 133 (2005) 61-87. doi:10.1007/s10704-005-2183-0.

[31] D. Hills, D. Dini, Characteristics of the process zone at sharp notch roots, International Journal of Solids and Structures 48 (14-15) (2011) 2177-2183. doi:10.1016/j.ijsolstr.2011.03.023.

[32] W.D. Pilkey and D.F. Pilkey, Peterson's Stress Concentration Factors, 3rd Edition, Wiley, 2008, ISBN: 978-0-470-04824-5.

[33] M. Ayatollahi, A. Torabi, A. Rahimi, Brittle fracture assessment of engineering components in the presence of notches: A review, Fatigue and Fracture of Engineering Materials and Structures 39 (3) (2016) 267-291. doi:10.1111/ffe.12379.

[34] F. Berto, P. Lazzarin, P. Livieri, On the second non-singular stress term of the V-notch solution: A new engineering solution, International Journal of Fracture 181 (1) (2013) 83-98. doi:10.1007/s10704-013-9822-7. 